\title{
Immediate Smoking Cessation Among People Living with HIV
}

\author{
Davood Yadegarynia, ${ }^{1}$ and Sara Rahmati Roodsari ${ }^{1,}$ \\ ${ }^{1}$ Infectious Diseases and Tropical Medicine Research Center, Shahid Beheshti University of Medical Sciences, Tehran, IR Iran \\ "Corresponding author: Sara Rahmati Roodsari, Infectious Diseases and Tropical Medicine Research Center, Shahid Beheshti University of Medical Sciences, Tehran, IR Iran. Tel: \\ +98-2122439963-8, Fax: +98-2122439964, E-mail: s_r_r85@yahoo.com \\ Received 2017 February 06; Accepted 2017 March 26.
}

Keywords: Smoking Cessation, HIV

Smoking, among HIV-infected individuals, is also a major cause of morbidity and mortality (1-3). Over $40 \%$ of HIVinfected people in the United States smoke; additionally $20 \%$ are former smokers (4). Furthermore, HIV-infected smokers seem to face higher rates of cardiovascular disease, chronic obstructive pulmonary disease, and numerous primary cancers compared with rates expected from smoking itself (5-7). However, antiretroviral therapy (ART) has improved their life expectancy $(8,9)$. HIV-infected individuals are now living long enough to develop smokingassociated diseases. Unfortunately, in HIV care, smoking cessation interventions have not been widely implemented.

HIV increases the risk of lung cancer, independently. In a validated microsimulation model of HIV, they applied standard demographic data and recent HIV/AIDS epidemiology statistics with specific details on smoking exposure, combining smoking status (current, former, or never) and intensity (heavy, moderate, or light). They have reported that mortality rates are attributable to lung cancer and other non-AIDS-related leads by smoking exposure and accounted for an HIV-conferred independent risk of lung cancer. For male and female, lung cancer mortality risk ratios (vs. non smokers) current moderate smokers were 23.6 and 24.2, respectively. In addition, those who quit smoking at age 40 years were 4.3 and 4.5 . In the sensitivity analyses, we accounted for non-adherence to antiretroviral therapy (ART) and for a range of HIV-conferred risks of death from lung cancer and from other non-AIDS-related diseases (e.g., cardiovascular disease) (10).

The main outcomes and measures demonstrated cumulative lung cancer mortality by the age of 80 (stratified by sex, age at entry to HIV care, and smoking exposure); total expected lung cancer deaths accounting for non-adherence to ART (10).

The results demonstrated that among 40-year-old men with HIV, estimated cumulative lung cancer mortality for heavy, moderate, and light smokers who continued to smoke was $28.9 \%, 23.0 \%$, and $18.8 \%$, respectively, for those who quit smoking at the age of 40 , it was $7.9 \%, 6.1 \%$, and $4.3 \%$, and for non smokers, it was $1.6 \%$. The corresponding mortality for current smokers was $27.8 \%, 20.9 \%$ in women, and $16.6 \%$, for former smokers, it was $7.5 \%$, 5.2\%, and $3.7 \%$, and for non smokers, it was $1.2 \%$. ART-adherent individuals who continued to smoke were 6 to 13 times more likely to die from lung cancer rather than from traditional AIDS-related causes, depending on sex and smoking intensity. Individuals with incomplete ART adherence had a higher overall mortality due to greater AIDS-related mortality risks but lower lung cancer mortality. Applying model projections to approximately 644,200 PLWH aged 20 to 64 in the United States, 59,900 (9.3\%) are expected to die from lung cancer if smoking habits do not change (10).

We concluded that those PLWH who adhere to ART but smoke are substantially more likely to die from lung cancer than from AIDS-related causes.

In Iran, expansion of the criteria for including more patients on treatment of HIV with any CD4 cell count is appearing on increasing life expectancy of patients living with HIV. Therefore, the priority of smoking cessation among HIV population is one of the major concerns for a better quality of life.

\section{References}

1. Crothers K, Goulet JL, Rodriguez-Barradas MC, Gibert CL, Oursler $\mathrm{KA}$, Goetz MB, et al. Impact of cigarette smoking on mortality in HIV-positive and HIV-negative veterans. AIDS Educ Prev. 2009;21(3 Suppl):40-53. doi: 10.1521/aeap.2009.21.3_supp.40. [PubMed: 19537953].

2. Lifson AR, Neuhaus J, Arribas JR, van den Berg-Wolf M, Labriola AM, Read TR, et al. Smoking-related health risks among persons with HIV in the Strategies for Management of Antiretroviral Ther- 
apy clinical trial. Am J Public Health. 2010;100(10):1896-903. doi: 10.2105/AJPH.2009.188664. [PubMed: 20724677].

3. Pines H, Koutsky L, Buskin S. Cigarette smoking and mortality among HIV-infected individuals in Seattle, Washington (1996-2008). AIDS Behav. 2011;15(1):243-51. doi: 10.1007/s10461-010-9682-3. [PubMed: 20390335].

4. Mdodo R, Frazier EL, Dube SR, Mattson CL, Sutton MY, Brooks JT, et al. Cigarette smoking prevalence among adults with HIV compared with the general adult population in the United States: cross-sectional surveys. Ann Intern Med. 2015;162(5):335-44. doi: 10.7326/M14-0954. [PubMed: 25732274].

5. Rasmussen LD, Helleberg M, May MT, Afzal S, Kronborg G, Larsen CS, et al. Myocardial infarction among Danish HIV-infected individuals: population-attributable fractions associated with smoking. Clin Infect Dis. 2015;60(9):1415-23. doi:10.1093/cid/civ013. [PubMed: 25595744].

6. Crothers K, Huang L, Goulet JL, Goetz MB, Brown ST, RodriguezBarradas MC, et al. HIV infection and risk for incident pulmonary diseases in the combination antiretroviral therapy era. Am J Respir Crit Care Med. 2011;183(3):388-95. doi: 10.1164/rccm.201006-08360C.
[PubMed: 20851926].

7. Helleberg M, Gerstoft J, Afzal S, Kronborg G, Larsen CS, Pedersen $\mathrm{C}$, et al. Risk of cancer among HIV-infected individuals compared to the background population: impact of smoking and HIV. AIDS. 2014;28(10):1499-508. doi: 10.1097/QAD.0000000000000283. [PubMed: 24785952].

8. Walensky RP, Paltiel AD, Losina E, Mercincavage LM, Schackman BR, Sax PE, et al. The survival benefits of AIDS treatment in the United States. J Infect Dis. 2006;194(1):11-9. doi: 10.1086/505147. [PubMed: 16741877].

9. Samji H, Cescon A, Hogg RS, Modur SP, Althoff KN, Buchacz K, et al. Closing the gap: increases in life expectancy among treated HIV-positive individuals in the United States and Canada. PLoS One. 2013;8(12):81355. doi: 10.1371/journal.pone.0081355. [PubMed: 24367482].

10. Reddy KP, Kong CY, Hyle EP, Baggett TP, Huang M, Parker RA, et al. Lung Cancer Mortality Associated With Smoking and Smoking Cessation Among People Living With HIV in the United States. JAMA Intern Med. 2017 doi: 10.1001/jamainternmed.2017.4349. [PubMed: 28975270]. 